\title{
Simulation of the Westinghouse AP1000 Response to SBLOCA Using RELAP/SCDAPSIM
}

\author{
Ayah Elshahat, ${ }^{1}$ Timothy Abram, ${ }^{2}$ Judith Hohorst, $^{3}$ and Chris Allison ${ }^{3}$ \\ ${ }^{1}$ Nuclear \& Radiation Engineering Department, Faculty of Engineering, Alexandria University, Alexandria 21544, Egypt \\ ${ }^{2}$ Centre for Nuclear Energy Technology, University of Manchester, Manchester, M13 9PL, UK \\ ${ }^{3}$ Innovative Systems Software (ISS), Ammon, ID 83406, USA \\ Correspondence should be addressed to Ayah Elshahat; ayahabouelnaga@hotmail.com
}

Received 20 August 2014; Revised 23 November 2014; Accepted 23 November 2014; Published 16 December 2014

Academic Editor: Arkady Serikov

Copyright (C) 2014 Ayah Elshahat et al. This is an open access article distributed under the Creative Commons Attribution License, which permits unrestricted use, distribution, and reproduction in any medium, provided the original work is properly cited.

\begin{abstract}
Great interest is given now to advanced nuclear reactors especially those using passive safety components. The Westinghouse AP1000 Advanced Passive pressurized water reactor (PWR) is an 1117 MWe PWR designed to achieve a high safety and performance record. The AP1000 safety system uses natural driving forces, such as pressurized gas, gravity flow, natural circulation flow, and convection. In this paper, the safety performance of the AP1000 during a small break loss of coolant accident (SBLOCA) is investigated. This was done by modelling the AP1000 and the passive safety systems employed using RELAP/SCDAPSIM code. RELAP/SCDAPSIM is designed to describe the overall reactor coolant system (RCS) thermal hydraulic response and core behaviour under normal operating conditions or under design basis or severe accident conditions. Passive safety components in the AP1000 showed a clear improvement in accident mitigation. It was found that RELAP/SCDAPSIM is capable of modelling a LOCA in an AP1000 and it enables the investigation of each safety system component response separately during the accident. The model is also capable of simulating natural circulation and other relevant phenomena. The results of the model were compared to that of the NOTRUMP code and found to be in a good agreement.
\end{abstract}

\section{Introduction}

Nuclear energy is increasingly considered as an attractive energy source that can deliver an answer to increasing worldwide energy demands. One of the most important public concerns, when dealing with nuclear energy, is the safety of nuclear power reactors. The main safety concern is the emission of uncontrolled radiation into the environment which could cause harm to humans at both the reactor site and off-site. Therefore, it is important to evaluate the safety performance of nuclear reactors.

Great interest is now given to advanced nuclear reactors especially those using passive safety components. Passive safety systems are used to provide significant improvements to plant simplification, safety, reliability, investment protection, and capital costs.

The Westinghouse Advanced PWR, AP1000, design includes advanced passive safety features and extensive plant simplification to enhance the safety, construction, operation, and maintenance of the plant. The Westinghouse AP1000 Advanced Passive pressurized water reactor (PWR) is an 1117 MWe 2-LOOP PWR based closely on the AP600 design. The AP1000 maintains the AP600 design configuration, the use of proven components, and the licensing basis by limiting the changes to the AP600 design to as few as possible [1]. The AP1000 safety systems use natural driving forces, such as pressurized gas, gravity flow, natural circulation flow, and convection [2].

In a previous work [3], a model for assessing the safety performance of nuclear reactors was developed using a Global Safety Index (GSI) model. The model was developed by introducing three indicators: probability of accident occurrence, performance of safety system in case of an accident occurrence, and the consequences of the accident. Investigation of the improvement in nuclear safety using advanced reactors was done by comparing the safety performance of a conventional reactor which uses active safety systems, such as PWR, with an advanced reactor which uses 
passive safety systems, such as the AP1000, during a design basis accident, such as loss of coolant accident (LOCA), using PCTran [4] as the simulation code. The safety performance of AP1000 is found to be better than that of a conventional PWR. It was needed to study the AP1000 safety performance in a more detailed model to investigate the passive safety systems employed.

In this work, a model of the AP1000 was developed using RELAP/SCDAPSIM [5] to simulate the passive core cooling system components and to investigate the performance of the different passive safety systems during a small break loss of coolant accident (SBLOCA).

\section{RELAP/SCDAPSIM Code}

2.1. Difference between RELAP/SCDAPSIM and PCTran. RELAP/SCDAPSIM is an advanced best-estimate computer code designed for simulating severe reactor accidents. The code predicts the thermal hydraulic response of the reactor coolant system (RCS) under normal operating conditions or under design basis or severe accident conditions [6].

The RELAP5 models calculate the overall RCS thermal hydraulic response, control system behaviour, reactor kinetics, and the behaviour of special reactor system components such as valves and pumps. The SCDAP models calculate the behaviour of the core and vessel structures under normal and accident conditions.

RELAP/SCDAPSIM has complete flexibility that allows modelling individual components, separate subsystems, or entire reactor complex with fully integrated control system logic [7].

On the other hand, PCTran is a simple reactor transient and accident simulation software program that operates on a personal computer. It is used mainly for educational and training purposes; hence, it is not recommended to be used for severe accident analysis. PCTran does not have the capability to investigate the effects of changing some parameters related to the accident severity and mitigation. It does not have the ability to remove or add different components. It also does not allow the study and investigation of different passive safety systems individually.

For the reasons mentioned above, RELAP/SCDAPSIM is used in this paper to develop a model of the AP1000 to investigate the effect of using passive safety systems in accident mitigation.

2.2. Different Versions of RELAP5/SCDAPSIM. There are many different versions of RELAP/SCDAPSIM; MOD3.2 is the oldest version and includes the publicly available RELAP and SCDAP models released by the US Nuclear Regulatory Commission (USNRC). MOD3.4 is the current production version. MOD4.0 is the latest experimental version and includes expanded models and user options. It has the most advanced code architecture, coding, numerics, and RELAP5 modelling options such as advanced water properties, alternative fluids, and an integrated uncertainty analysis package [7].

RELAP/SCDAPSIM MOD 3.5 has the most advanced SCDAP modelling options (the new QUENCH/PARAM-
ETER-experiment-driven SCDAP models). The new SCDAP modelling options include (a) an improved fuel rod gap conductance model, (b) improvements in the electrically heated fuel rod simulator model, (c) improvements in the shroud model, and (d) models to treat the influence of air ingression.

RELAP/SCDAPSIM MOD 3.5 runs a much wider variety of transients faster and more reliably than RELAP5/MOD 3.3 or RELAP5-3D. Also it is more accurate for many transient conditions particularly for those involving core temperatures in excess of $1000 \mathrm{~K}[6]$.

For the reasons mentioned above, it was decided to use MOD 3.5 to model the AP1000 as it is capable of modelling severe accidents, such as a LOCA, and it is able to model the passive safety systems' components with high accuracy.

\section{AP1000 RELAP5/SCDAPSIM Model}

3.1. AP1000 Plant Description. The reactor vessel is cylindrical, with a hemispherical bottom head and a removable hemispherical upper head. The vessel contains the core, core support structures, control rods, and other components directly associated with the core. The coolant and moderator are light water at a normal operating pressure of $15.5 \mathrm{MPa}$. The fuel, internals, and coolant are contained within a heavy walled reactor pressure vessel. An AP1000 fuel assembly consists of 264 fuel rods in a $17 \times 17$ square array [8].

The AP1000 steam generator (SG) is a vertical shell and Utube evaporator with integral moisture separating equipment. Design enhancements include nickel-chromium-iron alloy 690 thermally treated tubes a in triangular pitch, improved antivibration bars, single-tier separators, enhanced maintenance features, and a primary-side channel head design for easy access and maintenance by robotic tooling.

The AP1000 reactor coolant pumps are high-inertia, highreliability, low-maintenance, sealless pumps of either canned motor or wet winding motor design that circulate the reactor coolant through the reactor vessel, loop piping, and steam generators.

Reactor coolant system piping is configured with two identical main coolant loops, each of which employs a single 31-inch inside diameter hot leg pipe to transport reactor coolant to a steam generator. Two 22-inch inside diameter cold leg pipes in each loop (one per pump) transport reactor coolant back to the reactor vessel to complete the circuit [9].

The AP1000 pressurizer is a vertical, cylindrical vessel with hemispherical top and bottom heads, where liquid and vapour are maintained in equilibrium saturated conditions. One spray nozzle and two nozzles for connecting the safety and depressurization valve inlet headers are located in the top head. Electrical heaters are installed through the bottom head.

3.2. AP1000 Safety Systems Description. The passive core cooling system protects the plant against reactor coolant system leaks and ruptures of various sizes and locations. The passive core cooling system provides the safety functions of core residual heat removal, safety injection, and depressurization as shown in Figure 1. 


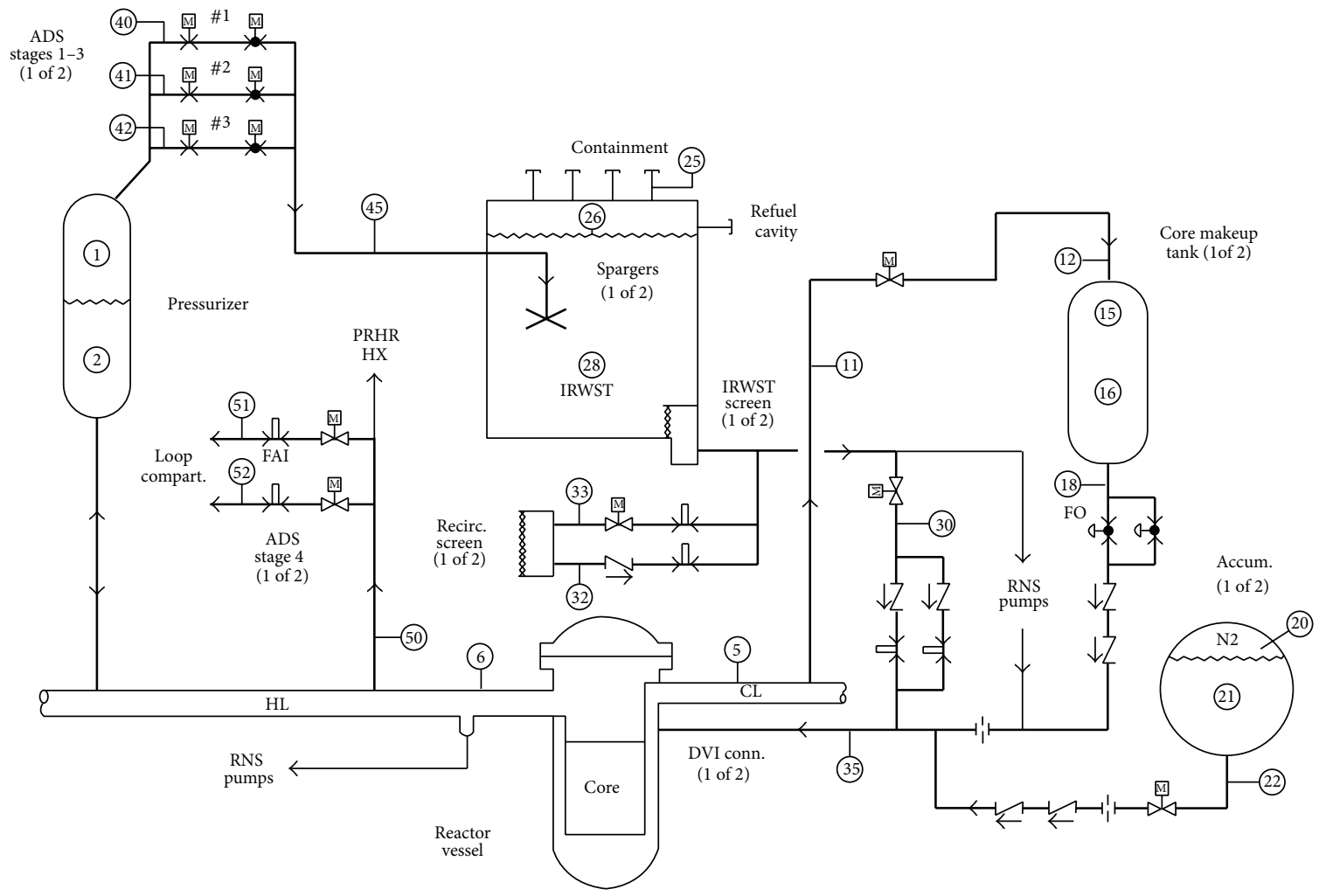

FIGURE 1: AP1000 passive core cooling system [8].

3.2.1. Core Make-Up Tank (CMT). The core make-up tanks replace the high-pressure safety injection systems in conventional PWRs. The two CMTs are located at an elevation above the core; they are filled with borated water and provide the reactor coolant system (RCS) makeup and boration for the loss of coolant accident (LOCA) and non-LOCA events when the normal makeup system is unavailable or insufficient. Each CMT consists of a large volume stainless steel tank with an inlet line that connects one of the cold legs to the top of the CMT and an outlet line that connects the bottom of the CMT to the direct vessel injection (DVI) line. The DVI line is connected to the reactor vessel downcomer. Each CMT is filled with cold borated water. The CMT inlet valve is normally open and hence the CMT is normally at primary system pressure. The CMT outlet valve is normally closed, preventing natural circulation during normal operation. When the outlet valve is open, a natural circulation path is established. Cold borated water flows into the reactor vessel and hot primary fluid flows upward into the top of the CMT [9].

The CMTs can operate in two different modes, depending on the RCS conditions. If the cold legs are filled with water, CMTs operate in a water recirculation mode with the driving force based on gravity and on the density difference between the hot reactor coolant in the CMT balance line and the colder water in the CMT. If the cold legs become voided, as they do during LOCAs, the CMTs will operate in a steam displacement injection or steam drain-down mode. In this mode, the driving force is based on gravity and the density difference between steam from the cold legs and water in the CMTs.
3.2.2. Passive Residual Heat Removal (PRHR). The passive residual heat removal heat exchanger (PRHR HX) is designed to use passive processes such as the gravity effect and natural circulation in its operation. It is the main component of PRHRS and is immersed in the in-containment refueling water storage tank (IRWST) which acts as heat sink. The PRHR HX consists of C-shaped tube bundle that is employed to remove core decay heat from the RCS for certain postulated accident events where a loss of cooling capacity via the steam generators occurs. The heat exchanger is maintained full of cold RCS coolant at full RCS pressure. The heat exchanger is connected to the RCS by an inlet line from one RCS hot leg through a tee from one of the fourth stage automatic depressurization lines [10].

3.2.3. Automatic Depressurization System (ADS). The automatic depressurization system consists of four stages of valves that provide for the controlled reduction of primary system pressure. The first three stages consist of two trains of valves connected to the top of the pressurizer. The first stage opens when CMT liquid level reaches $67.5 \%$ of its initial liquid level.

ADS stages two and three open shortly after a time delay of $70 \mathrm{sec}$ and $120 \mathrm{sec}$, respectively. The ADS 1-3 valves discharge primary system steam into a Sparger line that vents into the IRWST. The steam is condensed by direct contact with the highly subcooled water in the IRWST.

The fourth stage of the ADS consists of two large valves attached to ADS lines on each hot leg. The ADS- 4 valves open when the CMT liquid level is low (20\% of its initial level) and effectively bring primary-side pressure down to 
containment conditions. The ADS-4 valves vent directly into the containment building.

The first three stages of the ADS are represented by three parallel pipes connected to the pressurizer upper head and each flow path has two motor valves in series whose action is controlled by an open trip and a close trip in the input deck. The two ADS stage four paths are connected to the two hot legs, respectively, and the associated squib valves are modelled by trip valves [9].

\subsubsection{In-Containment Refueling Water Storage Tank (IRWST).} The in-containment refueling water storage tank is a very large concrete pool filled with cold borated water. It serves as the heat sink for the PRHR heat exchanger and a source of water for IRWST injection. The IRWST has two injection lines connected to the reactor vessel DVI lines. These flow paths are normally isolated by two check valves in series. When the primary pressure drops below the head pressure of the water in the IRWST, a flow path is established through the DVI into the reactor vessel downcomer. The IRWST water is sufficient to flood the lower containment compartments to a level above the reactor vessel head and below the outlet of the ADS-4 lines.

The IRWST is modelled as two connected fluid nodes (as done in the NOTRUMP code [11]). The lower node is connected to the direct vessel injection line and is the source of injection water to the DVI lines driven by a gravity head. The upper node acts as a sink for the ADS flow from the pressurizer and as a heat sink for the PRHR heat exchanger. These nodes are modelled as having an initial temperature of $322 \mathrm{~K}$ and a pressure of $101.35 \mathrm{kPa}$.

3.2.5. Accumulators (ACC). The accumulators are similar to those found in conventional PWRs. They are large spherical tanks approximately three-quarters filled with cold borated water and pre-pressurized with nitrogen. The accumulator outlet line is connected to the DVI line. A pair of check valves prevents injection flow during normal operating conditions. When system pressure drops below the accumulator pressure (plus the check valve cracking pressure), the check valves open allowing coolant injection to the reactor downcomer via the DVI line.

The ACC is modelled in RELAP5 as a lumped parameter component and therefore a nitrogen-charged accumulator and surge line system can be simulated [11].

\subsection{AP1000 Model Description. RELAP/SCDAPSIM/MOD3} input requirements can be divided into four distinct areas: hydrodynamics, heat structures, control systems, and neutronics. This model is mainly composed of hydrodynamic components that basically represent the parts of the reactor where coolant passes through and heat structures that represent solid parts of the reactor.

Owing to the proprietary nature of Westinghouse technical documentation, very little information related to design parameters and small break LOCAs in AP1000 can be obtained in the open literature. Therefore, some parameters have been assumed to be the same as in a conventional PWR
TABLE 1: AP1000 initial conditions.

\begin{tabular}{lc}
\hline Parameter & Initial value \\
\hline Core thermal power $(\mathrm{MW})$ & 3400.00 \\
Coolant volume flow per loop $\left(\mathrm{m}^{3}\right)$ & 35772.14 \\
RCS pressure $(\mathrm{MPa})$ & 15.52 \\
Vessel inlet temperature $(\mathrm{K})$ & 553.82 \\
Vessel outlet temperature $(\mathrm{K})$ & 594.26 \\
SG secondary pressure $(\mathrm{MPa})$ & 5.61 \\
SG feedwater temperature $(\mathrm{K})$ & 499.82 \\
SG feedwater temperature $(\mathrm{K})$ & 944.35 \\
Steam flow per SG $(\mathrm{kg} / \mathrm{s})$ & 28.32 \\
\hline
\end{tabular}

and some approximations have been applied to the developed model.

As the AP1000 is a two-loop PWR, each loop consists of one hot leg, two cold legs, one steam generator, and two canned motor pumps integrated into the steam generator channel head. The secondary side of the steam generator is simulated by a downcomer through which the main feedwater enters, a boiler consisting of the subcooled region and the boiling region, a separator where vapour-water separation occurs, and a steam dome connected to the steam header [11].

3.3.1. AP1000 Model Nodalization and Initial Conditions. In this model, a RELAP/SCDAPSIM model of the Surry reactor pressure vessel (RPV) is adopted and necessary changes were made to model the AP1000 pressure vessel. Some passive safety systems were modelled. The loop designated " $b$ " has the pressurizer and the PRHR system connections, and loop "a" cold legs have the core makeup tank pressure balance line connections as shown in the nodalization diagram, Figure 2. The initial conditions are listed in Table 1.

The core is composed of a downcomer (104) connecting to the lower head (106) and the lower plenum (108). The fuelled parts of the core are composed of five channels (111, $112,113,114$, and 115) and a bypass region (118). The upper plenum of the core is a 3-channel model ([151-152-153-154], [161-162-163-164], and [171-172-173-174]). The control assembly housing is represented in three parts $(181,182$, and 183). The upper head (190) covers the core and 100 and 102 represent upper annulus and inlet annulus, respectively.

Components 140-149 connect the centre core Channel 1 and centre core Channel 2. Components 120-129 connect the centre core Channel 2 and the middle core Channel 3. Components 80-89 connect the middle core Channel 3 and the middle core Channel 4 . Components 130-139 connect the middle core Channel 4 and the outer core Channel 5.

The pressurizer surge line and the hot and cold leg piping are constructed of stainless steel. The power operated relief valves (PORV) are located at the top of the pressurizer and can be used to relieve excess pressure in reactor coolant system (RCS). Pressurizer safety relief valves (SRV) are also available to handle pressure excursions in excess of the pressurizer PORV capacity.

The pipe 400 is the hot leg of the loop. The branch connects the pressurizer to the circuit. The pipe 443 represents the surge line. The pipe 441 represents the tank. The upper 


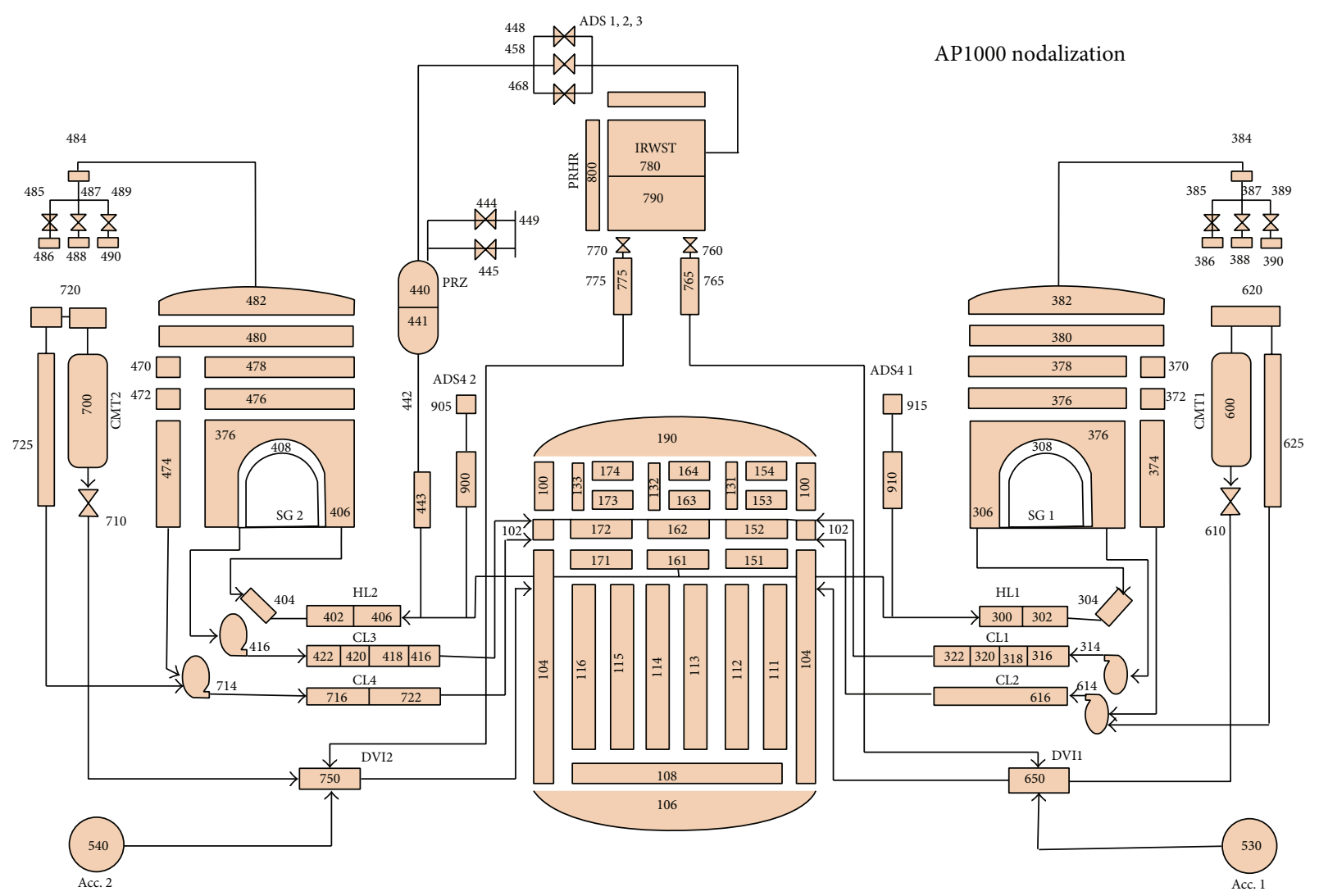

FIGURE 2: AP1000 nodalization.

part of this tank, the pressurizer dome (440), is represented by a branch-type element. Two valves $(444,445)$ connect the tank to a containment represented by a single volume (449). Their action is controlled by open trips 631 and 604 and close trips 633 and 606, respectively, in the input deck.

Two direct vessel injection (DVI) nozzles are located in the upper downcomer and safety injection water from CMTs, accumulators, IRWST, and containment sump is supplied through the nozzles. These nozzles are modelled as valves, 650 and 750 .

Each steam generator model includes a separator (378 and 478 resp.), motor valves $387,487,389$, and 489 ; pipes 374,474 , 376, 476, 308, and 408; branches 380, 480, 372, 472, 306, 406, 310 , and 410; time dependent junctions $385,485,367$, and 467; single volumes $370,470,304$, and 404; and time dependent volumes 366, 466, 390, 490, 388, 488, 386, and 486. The action of safety and PORV valves is controlled by open trips 610 and 619 and close trips 612 and 621, respectively, in the input deck.

There are many heat structures in the core, since all walls have conduction properties that cannot be neglected. All vessel walls, 100, thermal shields, 104 (in addition to the vessel walls, 106, 107, and 108), different structures and plates present in the core to maintain the assemblies and the integrity of the vessel, the core barrel, 201, and the core baffle, 151 , were modelled with heat structures. Also the cold and hot leg piping, steam generator tubes and shells, pump suction piping, and PRHRHX were represented by heat structures.
The pump included in this system is identical for each loop. It is possible to use the built-in pump models or to describe the characteristics of head and torque, pump head and torque multiplier, and two-phase difference curve.

\subsubsection{Modelling Safety System Components}

(1) Core Makeup Tank (CMT). Two CMTs, 600 and 700, are modelled as pipes consisting of 4 volumes each. CMT-1 (600) is connected through the discharge line, 610, to the direct vessel injection (DVI), 650, which is modelled as a single volume. From the top, CMT-1 (600) is connected through the balance line, 630 , to the cold leg, 618 , modelled as branch. The inlet and outlet valves are modelled as trip valves 630 and 610 . CMT-2 (700) is connected through the discharge line, 710, to the direct vessel injection (DVI), 750, which is modelled as a single volume. From the top CMT-2 (700) is connected through the balance line, 730 , to the cold leg, 320, modelled as branch. The inlet and outlet valves are modelled as trip valves 730 and 710 . The two valves, 610 and 710 , are adjusted to open after the RCS pressure reaches a value of $11.7 \mathrm{MPa}$, using trip card 625. Valves from the pressure balance line and the cold legs, 320 and 618, are adjusted to open just after the CMTs start to inject water, using trip card 642.

(2) Automatic Depressurization System (ADS). The first three stages of the ADS are modelled as valves, 448, 458, and 468, and are connected to the pressurizer upper head, 440 , and to 
TABLE 2: Set points for SBLOCA.

\begin{tabular}{ll}
\hline Event & Set point \\
\hline Reactor trip on low pressurizer pressure & $12.41 \mathrm{MPa}$ \\
Reactor trip on low-low pressurizer pressure & $11.72 \mathrm{MPa}$ \\
"S" signal on low-low pressurizer pressure & After reactor trip signal \\
PRHR isolation valve starts to open & After "S" signal \\
CMTs injection starts & After "S" signal \\
ACC injection starts on low RCS pressure & $4.83 \mathrm{MPa}$ \\
ADS-1 control valve trip signal & $20 \mathrm{~s}$ after $67.5 \%$ liquid volume fraction in CMT \\
ADS-2 control valve trip signal & $70 \mathrm{~s}$ after ADS- 1 actuation \\
ADS-3 control valve trip signal & $120 \mathrm{~s}$ after ADS-2 actuation \\
ADS-4A starts to open & $20.0 \%$ liquid volume fraction in CMT and $120 \mathrm{~s}$ after ADS-3 actuation \\
ADS-4B starts to open & $60 \mathrm{~s}$ after ADS- 4 A actuation \\
IRWST injection starts RCS pressure & RCS pressure less than $0.18 \mathrm{MPa}$ \\
\hline
\end{tabular}

the discharge line to the upper IRWST, 780. Their action is controlled by open trip 629 and close trip 627 in the input deck. The fourth stage of ADS is modelled as two valves, 905 and 915 . One side of valve 905 is connected to hot leg 400 in loop b, and the other side of the valve to containment 449. One side of valve 915 is connected to hot leg 300 in loop b, and the other side of the valve to containment 449 . Their action is controlled by open trip 630 and close trip 627.

(3) In-Refueling Water Storage Tank (IRWST). The IRWST is modelled as two connected nodes: a source, 790, and a sink, 780. The source 790 is connected (discharges) to the two DVIs, 650 and 750, through two valves, 770 and 760 . Their action is controlled by open trip 628. The sink, 780, is connected to the first three stages of ADS.

(4) Accumulator (ACC). There are two accumulators, 530 and 540 , driven by compressed nitrogen. Accumulator 1, 530, in loop (a) is connected to DVI1, 650. Accumulator 2, 540, in loop (b) is connected to DVI2, 750.

3.4. Description of the SBLOCA Scenario. For the safety analyses of the AP1000, a small break LOCA is defined as a rupture with a total cross-sectional area less than $1.0 \mathrm{ft}^{2}$ of the reactor coolant pressure boundary. This is considered a Condition III event (infrequent fault) that may occur during the life of the plant [8].

A 2 in. cold leg small break LOCA is simulated by adding a trip valve, 550, to the broken cold leg, 320, in the nonpressurizer loop. The set points for SBLOCA analysis are listed in Table 2.

\section{Results and Discussions}

A loss of coolant accident with 2-inch diameter break at the bottom of cold leg is simulated. The scenario of the accident can be analysed as follows. At $t=0 \mathrm{~s}$, a break was initiated in the cold leg by opening the LOCA valve. The primary system starts depressurization until the RCS pressure reaches the low value set point $(12.41 \mathrm{MPa})$, a reactor scram signal is generated, and the core thermal power falls rapidly to the

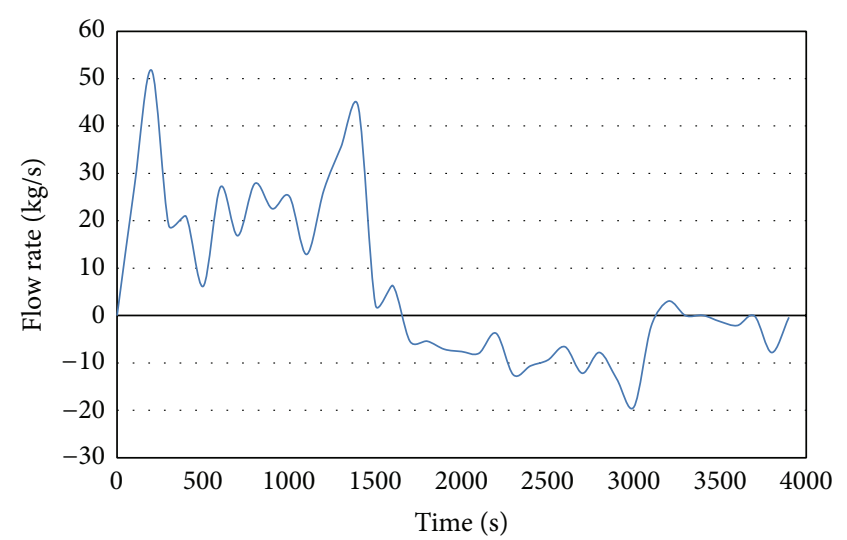

FIGURE 3: CMT injection flow rate during SBLOCA.

decay heat level with the effect of shutdown rods. The RCS continues depressurization till it reaches the low-low pressure set point (11.72 $\mathrm{MPa})$, which is the "S signal" and safety system actuation point. Then, both CMTs and PRHRHX are then activated.

The two CMTs are activated just after the "S" signal at about $t=10 \mathrm{sec}$ providing relatively high flow of borated water for a longer duration and with an increasing flow rate reaching a maximum value of $55 \mathrm{~kg} / \mathrm{sec}$ at $t=50 \mathrm{sec}$. After that the flow continues with a decreasing rate till both CMTs empty at $t=3200 \mathrm{sec}$ as shown in Figure 3. The time sequence of events is listed in Table 3.

Once the RCS pressure reaches $4.83 \mathrm{MPa}$, the accumulators begin to provide a high flow of borated water in a short time through the DVI lines. The accumulators are activated at $t=900 \mathrm{sec}$ with a flow rate starting at $81 \mathrm{~kg} / \mathrm{sec}$ which decreases until both accumulators empty at $t=1800 \mathrm{sec}$ as shown in Figure 4.

After the water level in both CMTs reaches $67.5 \%$ of their original value, the first three stages of automatic depressurization system (ADS) start depressurizing the RCS effectively. The first stage begins at $t=1600 \mathrm{sec}$ and the other two stages start with a delay of $70 \mathrm{sec}$ and $120 \mathrm{sec}$, respectively. 
TABle 3: Time sequence of events.

\begin{tabular}{lc}
\hline Event & Time \\
\hline Break opens & 0.0 \\
"S" signal & 10 \\
CMT discharge valves open & 10 \\
Accumulators injection starts & 900 \\
Accumulators emptied & 1800 \\
ADS1 starts & 1600 \\
ADS2 starts & 1670 \\
ADS3 starts & 1720 \\
ADS4 & 2100 \\
IRWST injection starts & 2800 \\
\hline
\end{tabular}

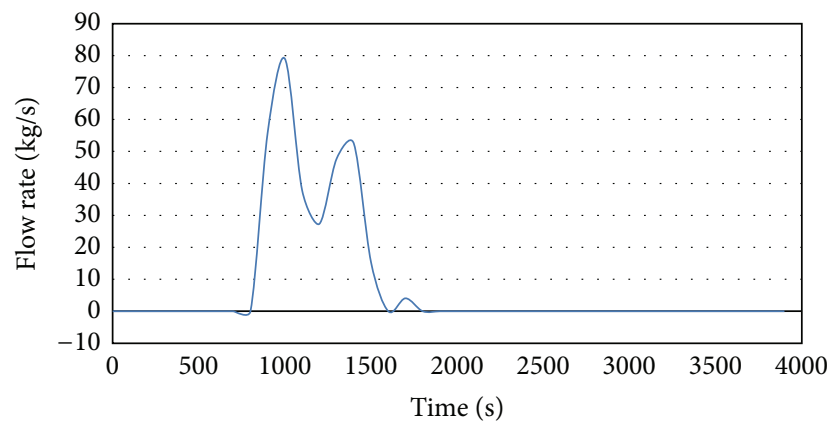

Figure 4: Accumulators' injection flow rates during SBLOCA.

After the water level in both CMTs reaches $20 \%$ of their original level, the fourth stage of ADS is activated at $t=$ $2100 \mathrm{sec}$ with a flow rate starting at $110 \mathrm{~kg} / \mathrm{sec}$ as shown in Figure 5.

After the primary system pressure drops to near the containment pressure, injection from the IRWST initiates. The IRWST is activated at $t=2800 \mathrm{sec}$ and provides low flow of borated water at an average flow rate of $50 \mathrm{~kg} / \mathrm{sec}$ and continues injection for longer time till the end of model scenario.

\section{Model Validation}

The results of the developed model will be compared in this section with the results of a 2 in. LOCA modelled by the NOTRUMP code [12] which is used by Westinghouse in [13].

Comparisons between the responses of different passive safety systems are illustrated in Figures 6-9.

5.1. CMT. Figure 6 shows the CMT response in NOTRUMP and in RELAP/SCDAPSIM. The graph shows the same injection rates in both models, but there is a difference in the end of injection time. This can be caused by the approximations and assumptions done in modelling the CMT by the RELAP/SCDAPSIM code.

5.2. Accumulators. Figure 7 shows the accumulator response in NOTRUMP and RELAP/SCDAPSIM. The results obtained from RELAP/SCDAPSIM model have the same trend of the

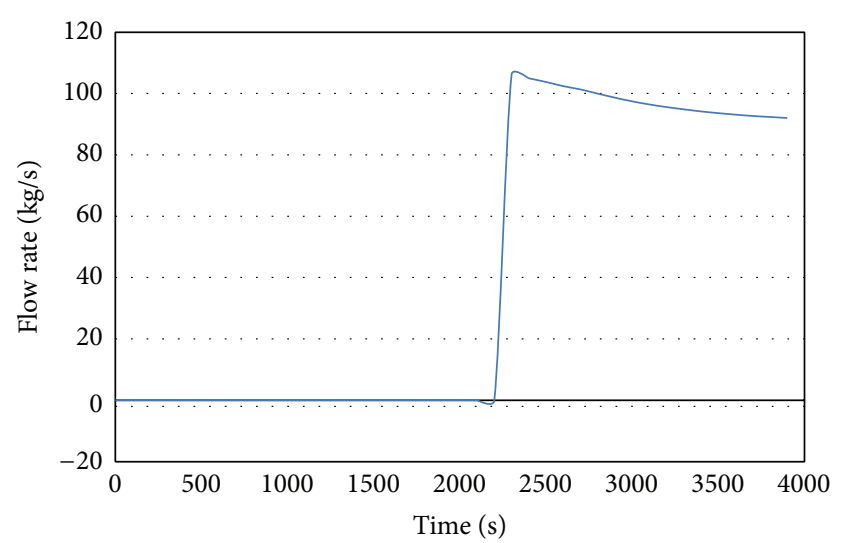

FIgURE 5: ADS4 injection flow rate during SBLOCA.

NOTRUMP and are in a good agreement in both initiation and end of injection times, but there is a difference in the injection flow rates.

5.3. ADS-4. Figure 8 shows the ADS4 response in NOTRUMP and RELAP/SCDAPSIM. The two models have the same average flow rates, $100 \mathrm{~kg} / \mathrm{sec}$, but there is a difference in the initiation of injection time. This can be caused by the assumptions made for some parameters when modelling ADS4 due to lack of design data.

5.4. IRWST. Figure 9 shows the IRWST response in NOTRUMP and RELAP/SCDAPSIM. There is a difference in the initiation time, but in both models the average flow rate is $50 \mathrm{~kg} / \mathrm{sec}$.

The calculated results obtained by RELAP/SCDAPSIM are consistent with those obtained using NOTRUMP. The main difference between them is the actuation times of passive systems which are partly due to the difference in the break discharge flow rate and also due to lack of available information in the literature on the AP1000 passive safety system design and the difficulty of deducing all these parameters. However, the results show, in most cases, the same trend in the response of each safety system during the SBLOCA, that is, the increasing flow rate.

\section{Conclusions}

The RELAP/SCDAPSIM model of Surry reactor (2-loop PWR) was adopted. Some modifications to the Surry model were made to model the passive safety components in the AP1000 and some changes to several parameters were also made. Many assumptions and approximations were made to the model due to the lack of the availability of many design parameters for the AP1000.

(i) The developed model for the AP1000 was used to evaluate the safety performance of an AP1000 during a small break LOCA. The passive safety components in the AP1000 showed a clear improvement in accident mitigation. 


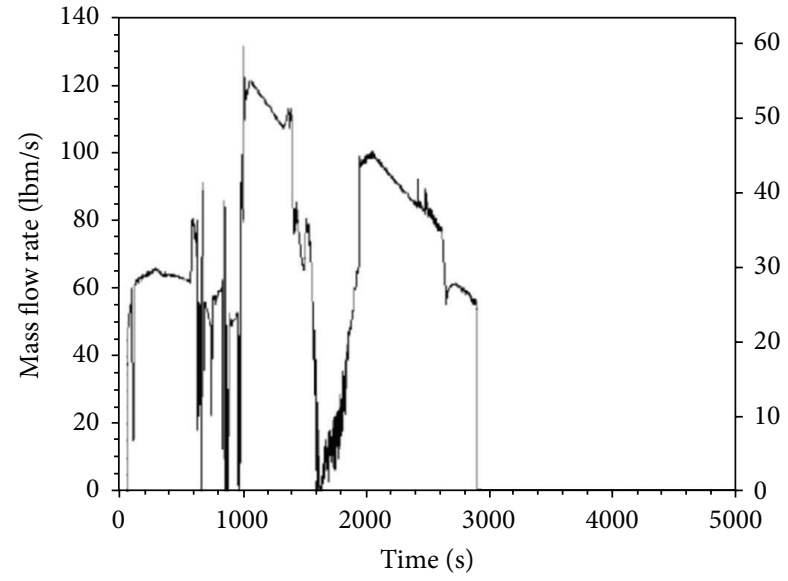

(a) NOTRUMP

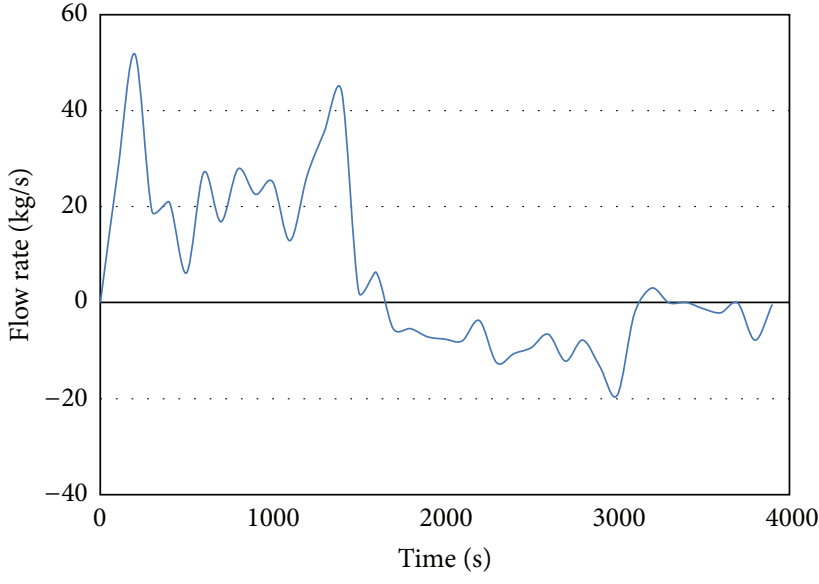

(b) RELAP/SCDAPSIM

FIGURE 6: CMT (1) injection flow rate during SBLOCA.

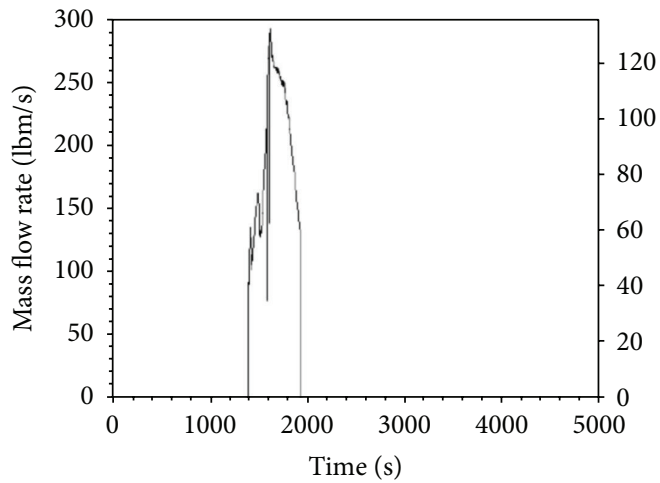

(a) NOTRUMP

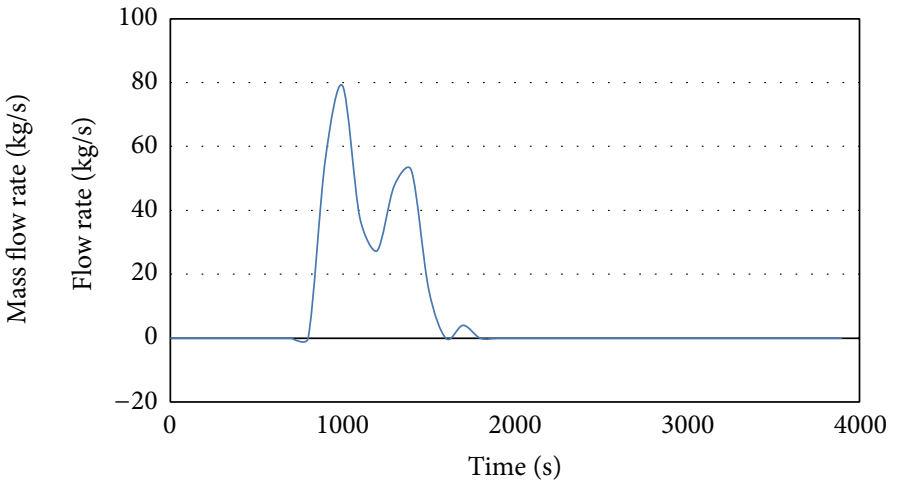

(b) RELAP/SCDAPSIM

Figure 7: Accumulator (1) injection flow rate during SBLOCA.

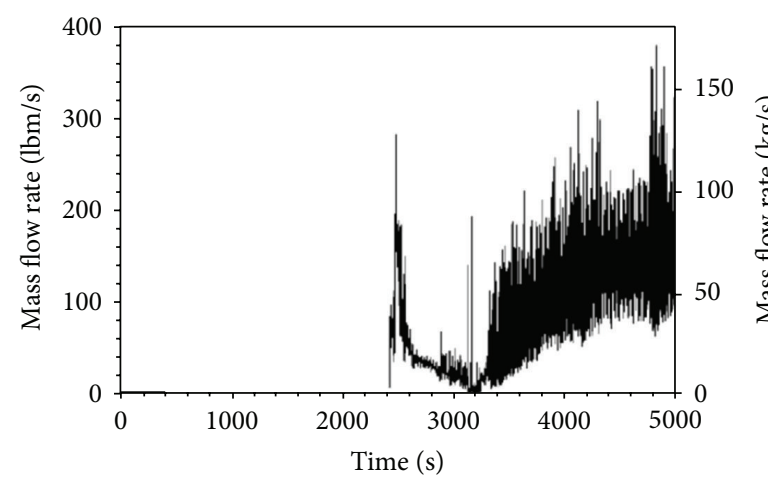

(a) NOTRUMP

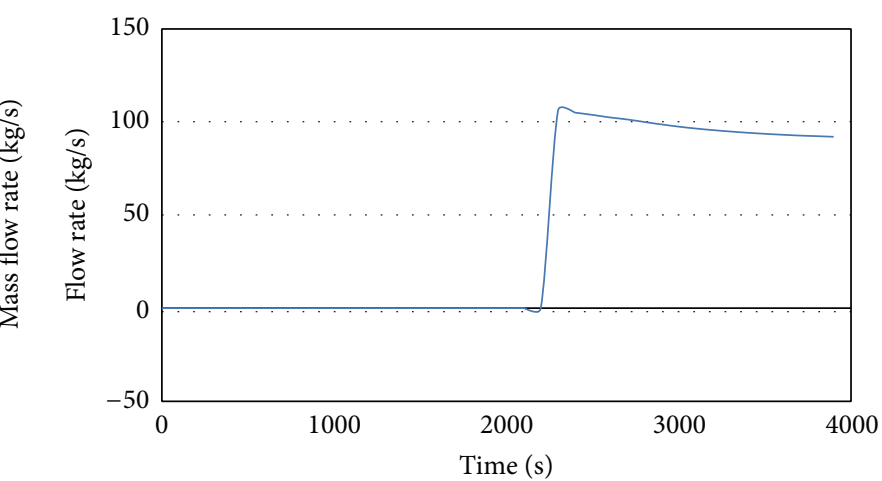

(b) RELAP/SCDAPSIM

FIGURE 8: ADS4 response during SBLOCA.

(ii) The passive safety systems were found to be capable of depressurizing the reactor coolant system while maintaining acceptable core conditions and establishing a stable delivery of cooling water from the IRWST. The AP1000 was found to have a good performance in mitigating SBLOCA consequences. These findings have important implications for enhancing the safety performance of nuclear reactors.

(iii) RELAP/SCDAPSIM was found to be a very good modelling tool for simulating different passive components of the AP1000 and to model a small break 


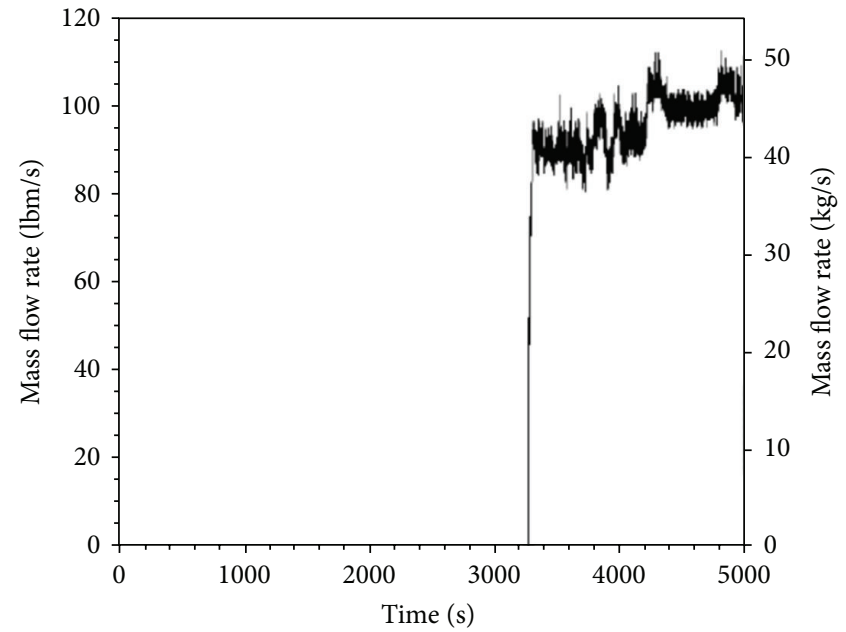

(a) NOTRUMP

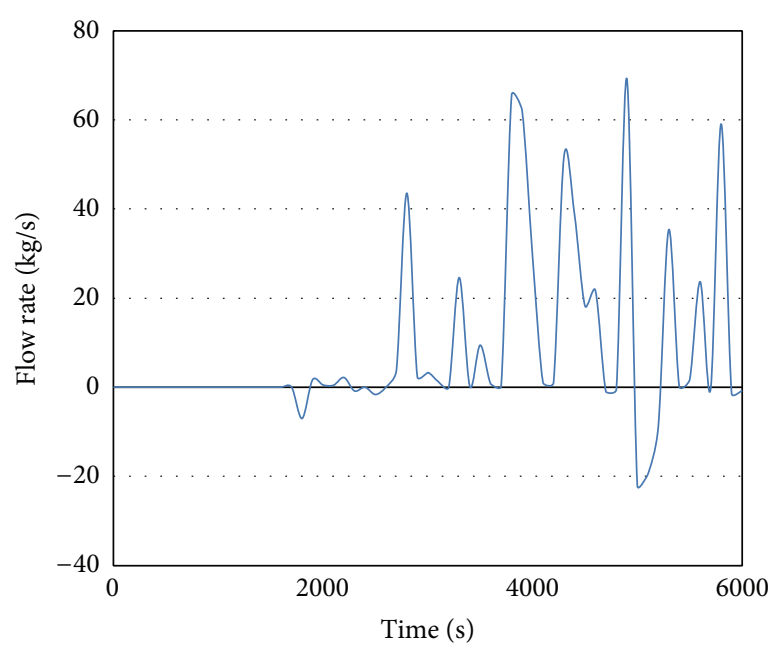

(b) RELAP/SCDAPSIM

FIGURE 9: IRWST injection flow rate during SBLOCA.

LOCA. The model was capable of modelling a LOCA in the AP1000 and enabled the investigation of each safety system component response separately during the accident. The model was also capable of simulating natural circulation and other different phenomena.

(iv) When comparing the results with that of the NOTRUMP code used by Westinghouse, they were found to have the same trends, but some differences in the initiation of safety systems were found. These differences are caused by the assumptions and approximations made by both codes and also because of the many assumed values for the design data used in the RELAP model due to the lack of published values for the AP1000 design parameters. However, the results show the same trend in the response of each safety system during the LOCA, that is, the increasing flow rate, the decreasing pressure, and so forth.

\section{Conflict of Interests}

The authors declare that there is no conflict of interests regarding the publication of this paper.

\section{Acknowledgments}

The authors would like to thank Professor Gianfranco Saiu and Dr. Monica Linda Frogheri in Ansaldo Energia for their sincere help and advice in making the nodalization of the AP1000.

\section{References}

[1] AP1000 Nuclear Power Plant BAT Assessment, Westinghouse Electric Company, 2011.
[2] G. Saiu and M. L. Frogheri, AP1000 Nuclear Power Plant Overview, ANSALDO Energia-Nuclear Division, Genoa, Italy.

[3] A. E. Abouelnaga, A. Metwally, N. Aly, M. Nagy, and S. Agamy, "Assessment the safety performance of nuclear power plants using Global Safety Index (GSI)," Nuclear Engineering and Design, vol. 240, no. 10, pp. 2820-2830, 2010.

[4] "PCTran for PWR and AP1000," Micro Simulation Technology, 2006.

[5] http://www.relap.com.

[6] C. M. Allison and J. K. Hohorst, Role of RELAP/SCDAPSIM in Nuclear Safety, Science and Technology of Nuclear Installations, 2010.

[7] L. J. Siefken, C. M. Allison, and J. K. Hohorst, "RELAP/SCDAPSIM/MOD3.5-improvements resulting from QUENCH and PARAMETER bundle heating and quenching experiments," in Proceedings of the 8th International Conference on Nuclear Option in Countries with Small and Medium Electricity Grids, Dubrovnik, Croatia, May 2010.

[8] Westinghouse AP1000 Design Control Document, Westinghouse Electric Company, 2004.

[9] T. L. Schulz, "Westinghouse AP1000 advanced passive plant," Nuclear Engineering and Design, vol. 236, no. 14-16, pp. 15471557, 2006.

[10] "Westinghouse AP1000 Design Control Document, ML11171A500, Rev. 19, Chapter 15: Accident Analyses," 2011.

[11] R. C. D. Team, "RELAP5/MOD3.3 Code Manual: NUREG/CR$5535 "$

[12] "NOTRUMP, a nodal transient small-break and general network code," Tech. Rep. WCAP-10079-P-A, 1985.

[13] Chapter 21. Testing and Computer Code Evaluation, "Final Safety Evaluation Report Related to Certification of the AP1000 Standard Design," Initial Report NUREG-1793. 


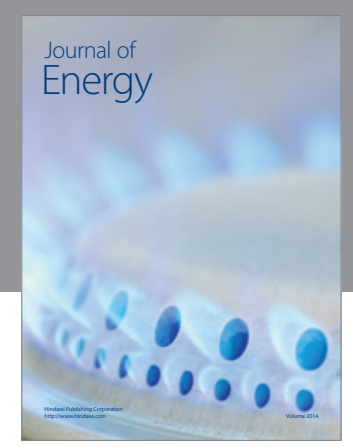

Journal of

Industrial Engineering
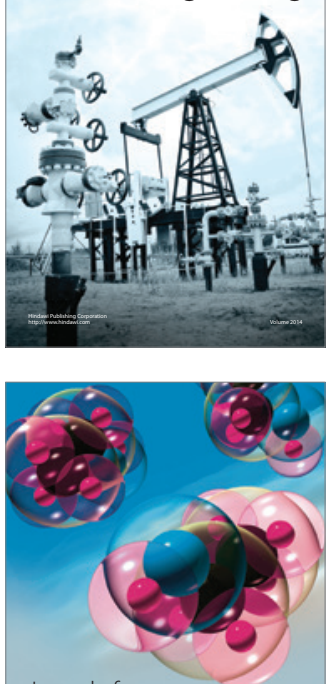

Fuels
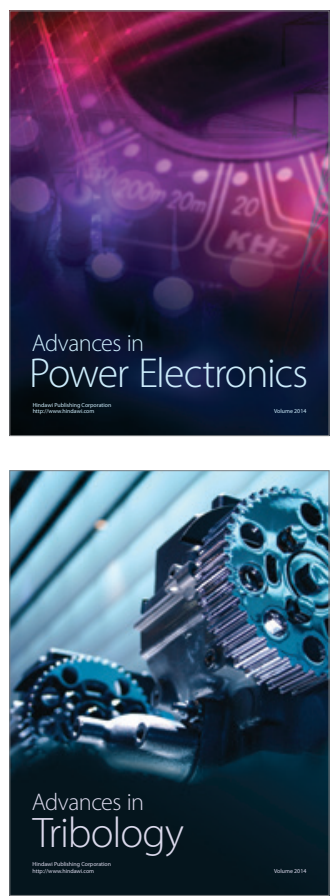

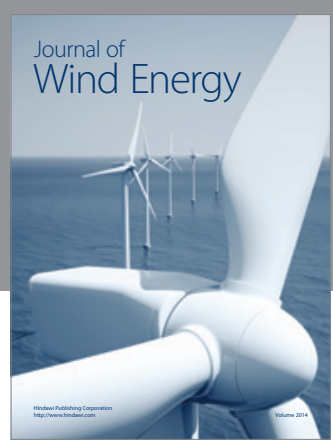

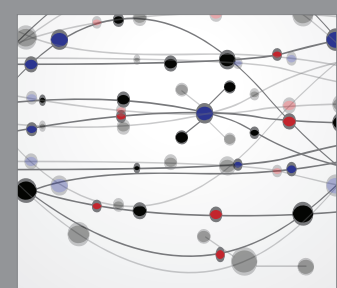

The Scientific World Journal

Submit your manuscripts at http://www.hindawi.com

Journal of

Structures
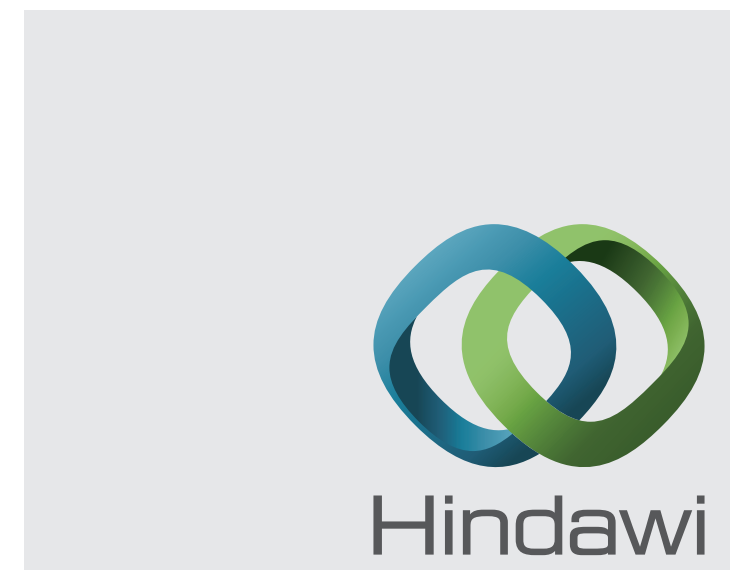

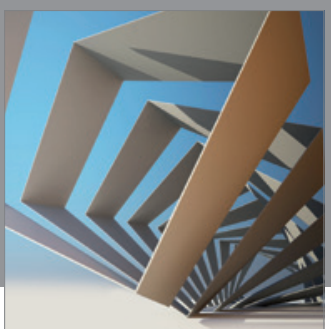

Rotating

Machinery
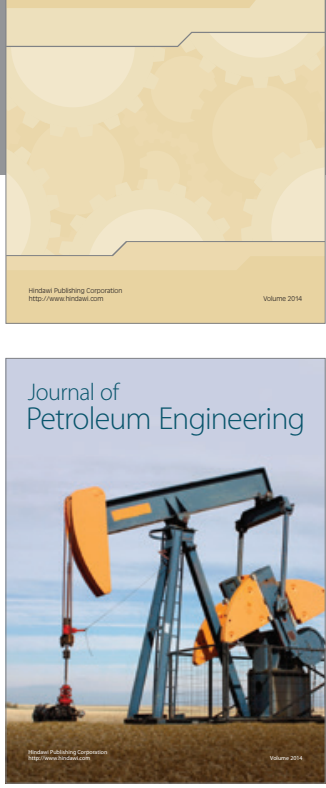

Journal of

Solar Energy
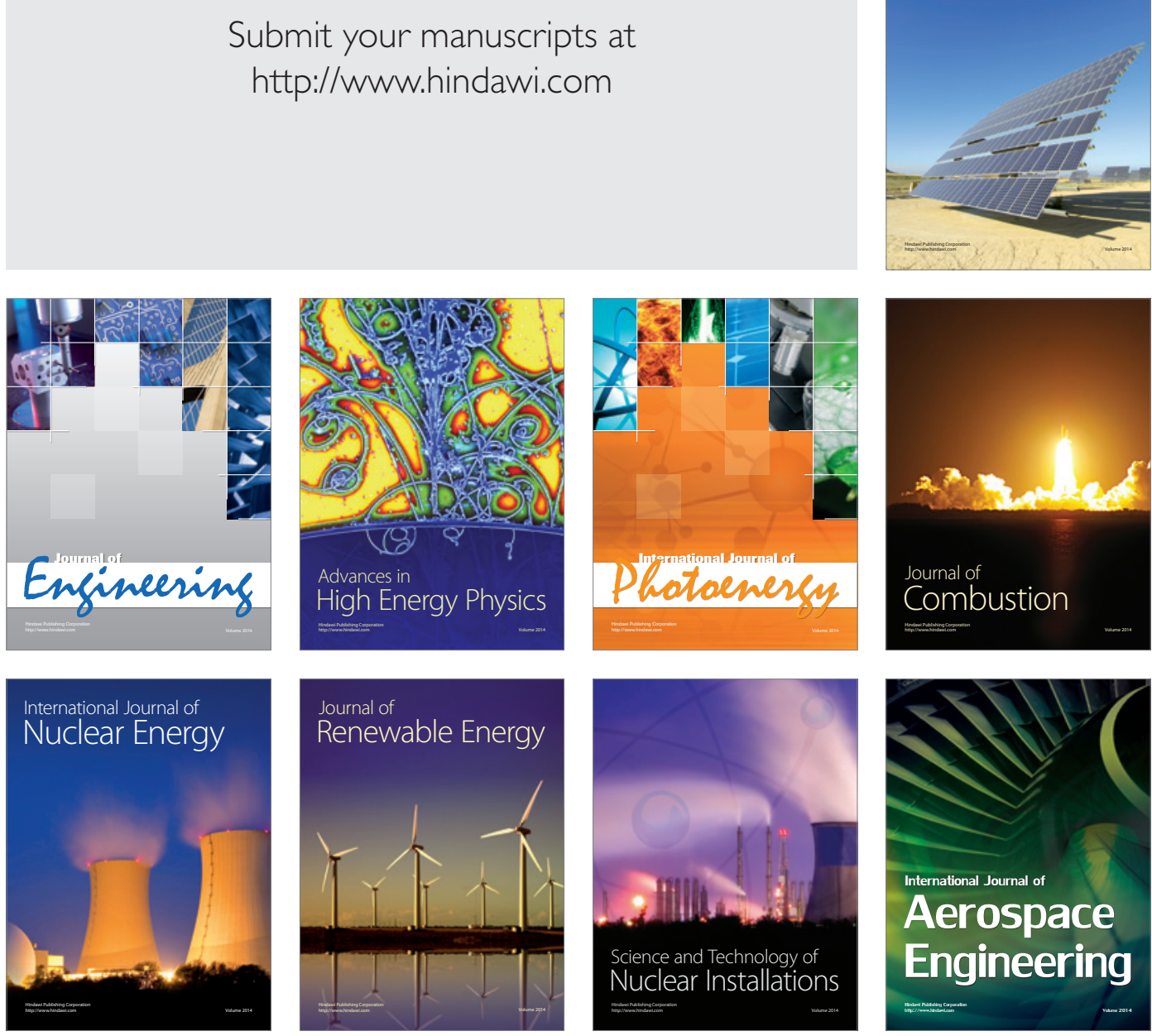